\title{
An Examination of Expert Discourse on Human Gene Editing Using Natural Language Processing
}

\author{
Micah MusseR* \\ Georgetown University \\ mrm311@georgetown.edu
}

\begin{abstract}
This research aims to explore the different ways in which scientists, ethicists, journalists, and official commissions speak to the public about new gene editing technologies. After building and preprocessing datasets of writings from each type of author, I examined frequencies of a number of key words, trained a sentiment classifier based on 5,000 hand-labeled sentences, and explored the type of sentiments used to discuss different issues. Key research questions included the degree of optimism or pessimism expressed by each type of author, the sentiment used in discussions about the global politics of gene editing, and the frequency with which key terms are used by each category of expert.
\end{abstract}

\section{INTRODUCTION}

$\longrightarrow$ N June 28, 2012, an international group of scientists published a paper in Science titled "A programmable dualRNA-guided DNA endonuclease in adaptive bacterial immunity,' 1 which demonstrated that the CRISPR-based systems found in many bacteria could be easily programmed to edit genes in living organisms. The Science article was not the first to identify the CRISPR system, nor was CRISPR the first gene editing system used by scientists to edit genes, nor was the public entirely unaware of the possibility of editing the human genome prior to the discovery of CRISPR. Nonetheless, the CRISPR system made gene editing vastly easier and, for the first time, raised the serious and immediate scientific possibility of editing human genes.

*Special thanks to Dr. Colin Farrelly, Dr. Nessa Carey, and Dr. George Church for graciously making copies of their books available for this research.

${ }^{1}$ M. Jinek, K. Chylinski, I. Fonfara, M. Hauer, J. A. Doudna, and E. Charpentier, "A programmable dual-RNAguided endonuclease in adaptive bacterial immunity," Science 17, no. 337 (August 2012): 816-821.
Public interest in gene editing has exploded since 2012, with an ever-increasing number of books, articles, movies, and podcasts seriously discussing the possibility of human genome editing. Governments have struggled to find a right balance on regulating the technology, and scientists have been divided over whether or not to call for a moratorium on the use of CRISPR technology to edit germline cells in humans 2 Numerous commissions have been convened to discuss the problem and journalists have published a steady flood of articles on the issue.

This article will aim to explore how professional experts on the topic of human genome editing attempt to engage or sway the public on this issue. There are four main groups of experts who have sought to develop and share their perspectives on gene editing with the public: scientists, bioethicists, journalists, and

\footnotetext{
${ }^{2}$ See Eric S. Lander et al., “Adopt a moratorium on heritable genome editing," Nature, March 13, 2019, https://www.nature.com/articles/d41586-01900726-5, which was signed by two of the three leading scientists responsible for developing the technology to use CRISPR in mammalian cells.
} 
members of government commissions. This article will attempt to explore how these groups communicate differently with the public using natural language processing techniques. The key questions that frame the analysis include the following:

1. Which groups tend to speak most positively about gene editing?

2. Do different types of experts pay disproportionate degrees of attention to particular issues related to CRISPR, such as its potential use in gene drives or the patent dispute between UC Berkeley and MIT regarding the rights to commercialize CRISPR-based technologies?

3. Which groups speak the most speculatively about the future of gene editing?

4. How is gene editing portrayed in an international context? Is emphasis put on the transnational nature of scientific collaboration, or on the danger of international competition with other countries, principally China?

5. Are there meaningful differences in the writings produced by government commissions of different countries?

6. How does the sentiment of journalists' coverage of gene editing issues respond to events in the news?

Almost all authors writing on gene editing agree that the technology has the potential to transform human society. For this reason, it is critically important to understand how the experts on the issue discuss it with the public.

Indeed, the experts themselves understand this to be true and often display an extremely high level of sensitivity to the precise language choices used by experts of other types. In her new book Altered Inheritance, for instance, bioethicist Françoise Baylis criticizes a perceived trend among scientists to gradually shift the threshold for the adoption of heritable human gene editing from that of a "broad societal consensus" to the less-demanding threshold of a "scientific consensus." ${ }^{3}$ Similarly, when a group of scientists and ethicists issued a call for a global moratorium on heritable gene edit-

\footnotetext{
${ }^{3}$ See Françoise Baylis, Altered Inheritance: CRISPR and the Ethics of Human Genome Editing (Cambridge: Harvard University Press, 2019), 209-213.
}

ing in humans in early 2019, other scientists objected, though in some cases their objections were largely to the use of the exact word "moratorium.' 4 This issue, in other words, has inspired not only a great deal of public interest but also a great deal of uneasiness and suspicion among experts regarding the way that others use language to sway public opinion.

This research aims to bring greater clarity to the developing discussion around gene editing by using natural language processing techniques to statistically compare large datasets of published writings. Although there are many limitations to the analysis (see Text Selection and Discussion), the results of this research aim to offer a more holistic account of the way that scientists, ethicists, journalists, and government commissions are approaching the issue of gene editing.

\section{Text Selection}

The texts used in this research fall into four bins: articles by journalists, books by scientists, books by ethicists, and official statements by commissions which are primarily governmentconvened or government-sponsored $5^{5}$ The list of reports by commissions was the easiest to obtain and the least subject to potential bias in text selection. The World Health Organization maintains an online list of commission

\footnotetext{
${ }^{4}$ This appears to be the position of Jennifer Doudna, the only one of the three leading CRISPR developers to not sign the call for a global moratorium. Her reasons, offered to reporters, appear to be largely based on the connotations of the word "moratorium," and not on the broad goals which a global moratorium would seek to achieve. See Sharon Begley, "Leading Scientists, Backed by NIH, Call for a Global Moratorium on Creating 'CRISPR Babies,'” STAT News, March 13, 2019, https:/ /www.statnews.com/2019/03/13/crisprbabies-germline-editing-moratorium/.

${ }^{5} \mathrm{Few}$ of these reports have been formally endorsed by legislative bodies, but most were produced by institutions - such as national ethics boards or national academies of science-that receive government funding and have some quasi-official capacity within the apparatus of the state. Others, such as the statements of the First and Second International Summits on Human Genome Editing, have no official relationship to any government, but were nonetheless organized in large part by academies of science from multiple countries.
} 
reports from around the world regarding human genome editing ${ }^{6}$ PDF versions of each of these commissions were used to build a dataset of over 21,000 sentences authored by commissions. Exclusions were made only if (1) an English version of the text was inaccessible or (2) the commission report was published prior to 2012 and therefore not related to the new wave of discourse regarding gene editing. It is important to note that these reports were authored by a wide range of commissions with different compositions; while some-such as the Nuffield Council in the United Kingdom-are meant to function as ethics boards, others-such as the National Academies of Science, Engineering, and Medicine-were composed by a mix of scientists and ethicists. A full list of the reports used in this research is shown in Table A1 in the Appendix.

The articles by journalists were collected using the ProQuest News and Newspapers database. I obtained this list by simply searching for all articles published between January 1, 2012 and December 9, 2019 which contained the word "CRISPR." After making some minor exclusions (such as eliminating results from tables of contents) and identifying nine major American and British newspapers with significant publications on the topic, a total of 904 articles were returned 7 The publications used and the number of articles from each are shown in Table 1. Additionally, a timeline showing the rate of newspaper publications mentioning CRISPR can be seen in Figure 1, along with a list of significant events relating to CRISPR from the past five years.

It was more difficult to identify appropriate texts by ethicists and scientists without introducing potential bias. Although scientists have written a great deal on gene editing, the core area of interest for this research is in public-

\footnotetext{
6"Information resources on Human Genome Editing," World Health Organization, accessed November 27, 2019, https://www.who.int/ethics/topics/humangenome-editing/resources/en/.

${ }^{7}$ It should be noted that, due to ProQuest's method of storing articles, some of these articles were duplicates and could not easily be removed from the dataset. I estimate that roughly 150 articles may have been duplicates.
}

Table 1: Sources of News Articles

\begin{tabular}{lr}
\hline Publication & Article Count \\
\hline Boston Globe & 253 \\
Wall Street Journal & 216 \\
Financial Times & 112 \\
New York Times & 97 \\
Washington Post & 74 \\
The Economist & 41 \\
The Guardian & 39 \\
MIT Technology Review & 39 \\
Los Angeles Times & 33 \\
Total & 904 \\
\hline
\end{tabular}

facing writings. Academic articles by scientists tend not to be public facing; instead, the primary means by which scientists communicate their perspectives with the public are through books, speeches, and articles in the popular press. Of these potential sources, books were selected as the media format that provided the most detailed samples of scientists' public thoughts on gene editing technologies. As with the other types of writing, only books written between 2012 and 2019 were included in the analysis. Five books were ultimately selected for inclusion in this research: Regenesis: How Synthetic Biology Will Reinvent Nature and Ourselves by George Church and Ed Regis, $\left.\right|^{8}$ Evolving Ourselves: Redesigning the Future of $\mathrm{Hu}$ manity-One Gene at a Time by Juan Enriquez and Steven Gullans 9 Modern Prometheus: Editing the Human Genome with Crispr-Cas9 by Jim Kozubek ${ }^{10}$ A Crack in Creation: Gene Editing and the Unthinkable Power to Control Evolution by Jennifer Doudna and Samuel Stenberg 11

\footnotetext{
${ }^{8}$ George Church and Ed Regis, Regenesis: How Synthetic Biology Will Reinvent Nature and Ourselves (New York: Basic Books, 2012). Dr. Church graciously made a copy of the 2012 text available for use in this research, as well as the text of a 2014 update for the second edition of the book, which explicitly discussed CRISPR.

${ }^{9}$ Juan Enriquez and Steve Gullans, Evolving Ourselves: Redesigning the Future of Humanity-One Gene at a Time (New York: Penguin Random House, 2016).

${ }^{10}$ Jim Kozubek, Modern Prometheus: Editing the Human Genome with Crispr-Cas9 (Cambridge: Cambridge University Press, 2016).

${ }^{11}$ Jennifer A. Doudna and Samuel H. Stenberg, A Crack
} 


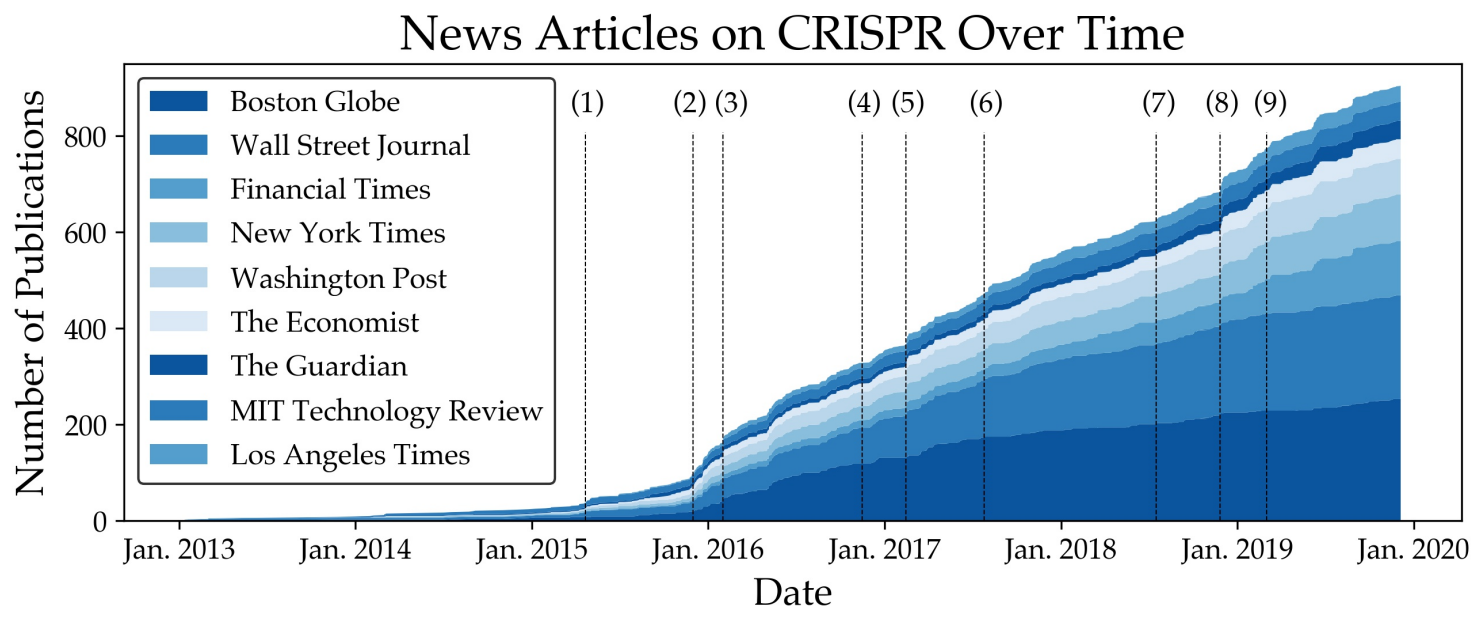

Figure 1: News Articles Mentioning CRISPR by Date and Source. Significant dates are marked with numbers and represent the following events: (1) the announcement of the first experiments on human embryos in China, (2) the meeting of the First International Summit on Human Genome Editing, (3) the announcement of approval for the first experiments on human embryos in the United Kingdom, (4) the announcement of the first clinical trials using CRISPR methods in China, (5) the release of the NASEM report in the United States, (6) the announcement of the first experiments on human embryos in the United States, (7) the release of the 2018 Nuffield Council report, (8) the announcement of the He Jiankui experiments, and (9) the publication of a call from leading scientists for a global moratorium on human germline gene editing.

and Hacking the Code of Life: How Gene Editing Will Rewrite Our Futures by Nessa Carey ${ }^{12}$

Similar logic was used to select writings by bioethicists on gene editing. Although perhaps more accessible to a public audience than scientific articles, articles in bioethics journals are still most likely to be intended for academic audiences. As with scientists, the dataset for ethicists was therefore again built by searching for books published after 2012 on the topic of gene editing. A total of four books were selected: The Ethics of Human Enhancement: Understanding the Debate ${ }^{13}$ Genetic Ethics: An Intro-

in Creation: Gene Editing and the Unthinkable Power to Control Evolution (New York: Houghton Mifflin Harcourt, 2017). Jennifer Doudna is one of the three leading researchers behind the development of CRISPR technology and by far the one of the three who has most aggressively committed herself to engaging in public debates around CRISPR, making this book particularly significant.

${ }^{12}$ Nessa Carey, Hacking the Code of Life: How Gene Editing Will Rewrite Our Futures (London: Icon Books, 2019). Dr. Carey also generously made a copy of her text available for use in this research, a gift that was graciously approved by her editor, Mr. Duncan Heath of Icon Books.

${ }^{13}$ Steve Clarke, Julian Savulescu, C. A. J. Coady, Alberto duction by Colin Farrelly $1{ }^{14}$ Human Flourishing in an Age of Gene Editing ${ }^{15}$ and Altered Inheritance: CRISPR and the Ethics of Human Genome Editing by Françoise Baylis ${ }^{16}$ Of these texts, both The Ethics of Human Enhancement and Human Flourishing in an Age of Gene Editing were compendiums of 17 essays each written by 23 and 20 different ethicists, respectively.

Some important caveats about the selection of texts must be made. First, none of the datasets are necessarily balanced among a wide range of voices. While there are over nine hundred news articles included in the analysis, only five books by scientists and four by ethicists were available. For that reason, this

Giubilini, and Sagar Sanyal, eds., The Ethics of Human Enhancement: Understanding the Debate (Oxford: Oxford University Press, 2016).

${ }^{14}$ Colin Farrelly, Genetic Ethics: An Introduction (Cambridge: Polity Press, 2018). Dr. Farrelly very kindly made a copy of the text of his book for use in this research.

${ }^{15}$ Erik Parens and Josephine Johnston, eds., Human Flourishing in an Age of Gene Editing (Oxford: Oxford University Press, 2019).

${ }^{16}$ Baylis, Altered Inheritance. 
Table 2: Number of Sentences by Author Type

\begin{tabular}{lr}
\hline Author Type & Sentence Count \\
\hline Ethicists & 15,362 \\
Scientists & 18,784 \\
Commissions & 21,412 \\
Journalists & 44,420 \\
Total & 99,978 \\
\hline
\end{tabular}

research uses as its units of analysis individual words and sentences, rather than complete texts. (The counts of sentences for each category are shown in Table 2.) This adaptation allows the four datasets to become comparably sized in terms of the major unit of analysis, but does not make the voices of the contributors themselves any more diverse. The news articles are taken from only nine publications and a large percentage were authored by under a dozen authors. Although many government reports were included, only five contain more than 1,000 sentences, with over a quarter of the analyzable text deriving from the February 2017 report of the National Academies of Sciences, Engineering, and Medicine (hereafter the NASEM report). There is therefore a danger that these few texts will to some extent overpower the influence of the others in a statistical analysis. Additionally, the small number of books by scientists and ethicists available indicate that only a few representative voices of each group are included in the analysis, though the problem is somewhat alleviated by the fact that two of the books by ethicists include writings by 20 or more individual authors.

A second caveat is that the decision to write a book on this subject, particularly when taken by scientists, is a strongly biasing factor. Government commissions, when convened to address a bioethical problem, are expected to produce a public-oriented piece of analysis, and the job of journalists is to write for the public. Many ethicists write principally in academic contexts for other academics; nonetheless, writing about moral and societal issues is core to the work of any bioethicist. Scientists, on the other hand, face no obligation to write about the implications of the research they conduct. For that reason, the perspectives expressed by the scientists whose work is used in this study will have already passed through at least one level of strong self-selection, in that only scientists who are deeply passionate about gene editing are likely to have written a book on the topic. It would therefore be unwise to assume that any results discovered in this study can be said to be representative of the views of scientists as a whole.

An additional caveat pertains to the function of the writing used by each type of author. As discussed, the audience of journalists and those scientists who have written public-facing books on this issue generally is meant to include members of the public of any level of knowledge who are at least somewhat interested in the issue of gene editing. The writings of government commissions, however, are meant to be read not only by ordinary constituents but also by regulators, policymakers, and members of other commissions. These writings therefore often take a more formal tone and can be said to function as semi-public in their orientation. A similar dynamic arises among ethicists. While some books are clearly intended for the broadest possible audience-Altered Inheritance, for instance, was deliberately written to avoid excessive use of jargon-others are written to be read as much by other ethicists as by members of the public. Many of the articles in The Ethics of Human Enhancement, for example, assume a reasonable familiarity with existing ethical frameworks and terminology. Some ethics books, then, are also more semi-public than fully public, and the topics addressed by ethicists in particular are not always strictly focused in gene editing. ("Human enhancement," for instance, is a broad term which includes but extends well beyond genetic editing.) While public and semi-public texts can to a large extent be reasonably compared, it is important to keep in mind that they may be intended to sway different audiences and accomplish different tasks.

A further complication arises from the fact that there is some overlap between the authors 
of different works and some ambiguity in assigning categorical labels to the different authors of these texts. Jim Kozubek, for instance, is both a trained scientist with a book on gene editing (including in the dataset for writings by scientists) and an occasional contributor to the Boston Globe with some articles included in the dataset for journalists. Françoise Baylis and Jennifer Doudna have both written books on gene editing (as an ethicist and a scientist, respectively) and have served on commissions that have written reports on gene editing. Although a book by Juan Enriquez and Steve Gullans is included in the bin for scientists, only Steve Gullans is trained as a scientist; Juan Enriquez is a businessman, and the two currently work to co-lead Excel Venture Management, an investment fund focusing on technologies from the life sciences. These overlaps are important to keep in mind, though not often extremely substantial in terms of the amount of text affected. In addition, the primary goal of this research is to explore how experts speak about gene editing when speaking in their capacity as experts of different types. It is therefore not a major problem if the same individual occasionally speaks about the issue as a representative of different expert groups, for the element of interest is to see whether they modulate their modes of expression in these different capacities.

Finally, it is worth noting that a number of significant writings have not been included in this analysis which might have been. This research makes no use of statements from important interest groups such as the Alliance for Regenerative Medicine or the Hinxton Group, nor does it include op-eds by groups of scientists. Such writings have had significant impact on the evolving debate over gene editing technologies and have been included in similar research ${ }^{17}$ however, I have not addressed them here. Instead, when it comes to official reports, my focus has been exclusively on reports from governments or government-sponsored com-

\footnotetext{
${ }^{17}$ See Carolyn Brokowski, "Do CRISPR Germline Ethics Statements Cut It?" The CRISPR Journal 1, no. 2 (April 1, 2018): $115-125$
}

missions and conferences, and I have used only those reports included in the WHO's online list or resources in order to minimize any potential bias in text selection on my part.

\section{Methods}

After collecting the texts which provided the raw data for this research, all writing was preprocessed into a more machine-readable format using the Natural Language Toolkit (NLTK) available in Python. Each individual file was first split into sentences using NLTK's sentence tokenizer, after which each individual file was stripped of punctuation and reduced to entirely lowercase letters ${ }^{18}$ Additionally, all text was converted to Standard American English and lemmatized. In text lemmatization, each individual word is marked with its part of speech and then converted to its root form. Text lemmatization allows a computer program to recognize multiple word variants as the same word and therefore to recognize a denser set of textual similarities between documents. After using NLTK's built-in functions to lemmatize the sentences, a list of stop words-or words that occur commonly in the English language but contain no informative content-was removed from each sentence 19 Finally, commonly recognized but false sentences were removed from the list of sentences before being returned in a new file ${ }^{20}$

\footnotetext{
${ }^{18}$ This step is necessary because Python programming is case-sensitive; "Crispr" and "CRISPR" would be interpreted as different words during data analysis if all text was not lowercased first.

${ }^{19}$ This research used a custom list of stop words which included not only a relatively small number of English words but also a list of "words" that were frequently returned in the preprocessing stage. For instance, documents that used "p." to indicate a page number in a citation were often filled with sentences that contained the "word" $p$. The full list of removed stop words was as follows: 'am', 'an', 'and', 'the', 'credit', 'to', 'for', 'above', 'across', 'at', 'around', 'before', 'behind', 'beside', 'between', 'by', 'down', 'during', 'from', 'in', 'inside', 'onto', 'of', 'off', 'on', 'out', 'through', 'with', 'be', 'have', 'or', 'it', 'a', 'that', 'we', 'this', 'our', 's', 'they', 'do', 'about', 'but', 'use', 'which', 'their', 'such', 'these', 'he', ' $t$ ', 'so', 'into', 'can', 'would', 'what', 'some', 'p', 'q', 'm', and 'ca'.

${ }^{20}$ For example, some texts were only available as PDFs which contained page headings such as "Copyright Na-
} 
The preprocessed sentences were then used to train a naive Bayes classifier. Before applying any classification techniques, a bag-of-words representation of the entire corpus was generated using Scikit-Learn's count vectorizer function. A bag-of-words representation returns an array indicating the number of times each word observed in the corpus occurs in a given sentence ${ }^{21}$ Following this step, a random sample of 61,448 sentences were taken in equal proportions from each of the four datasets and converted to numerical data using the fitted count vectorizer ${ }^{22}$ A naive Bayes classifier was then trained using $95 \%$ of these converted sentences and tested against the remaining 5\%. Naive Bayes classifiers are simple categorization programs that calculate the likelihood of any given word occurring in a text of a given class and predict the class of an input text by using these probabilities. After training, the naive Bayes classifier reached an accuracy of $73.1 \%$. A fuller analysis of the results of this classifier is provided in the Results section.

After building the text classifier, I examined the frequency of a number of key words across each author type. A description of the key words studied, the methods used to compare their frequencies, and the results are provided together in the Results section.

tional Academies of Science. All rights reserved." To ensure that these commonly occurring but meaningless sentences did not bias any results, the final list of sentences was combed for any such meaningless sentences that occurred more often than five times, and those sentences were removed from the datasets.

${ }^{21}$ This step used a number of specific parameters to increase the accuracy of the final classifier. Not only were individual words used in the count vectorizer, but so too were all pairs and triplets of words. This change allows a classifier model to recognize short patterns of words, e.g. "gene editing," as distinct vocabulary terms, and to interpret combinations of words, e.g. "not accessible," as containing meanings distinct from their individual components. In addition, best results were obtained by fitting the count vectorizer on a maximum of 25,000 terms and by excluding any words that occurred in over $90 \%$ of the input sentences. (Extremely common words are likely to carry little informative content and often have the effect of confusing a classifier model.)

${ }^{22}$ The number 61,448 represents the length of the smallest dataset (that for ethicists, which included 15,362 sentences) multiplied by four.
Another key goal of this research was to explore the sentiments used by each type of author to discuss gene editing. Achieving this task required a sentiment classifier, which in turn required data that had been labeled with different sentiment types. To build such a classifier, I randomly selected 5,000 sentences from journalists and labeled them as positive, negative, or neutral. I then repeated the classifier methodology used above, fitting a count vectorizer to the full list of sentences before training and testing a naive Bayes classifier on the labeled sentences ${ }^{23}$ Unfortunately, this sentiment classifier performed less well than the author classifier (see Figure 2). To compensate and increase the confidence in the predicted sentiment of any given sentence, I used the same data to train three additional models: a logistic regression classifier, a support vector machine, and a random forest classifier. Each model returned comparable overall results-the accuracy scores for the naive Bayes, logistic regression, support vector machine, and random forest classifiers were $59.25 \%$, $62.25 \%, 56.25 \%$, and $58.25 \%$, respectively-but made differing types of errors, as shown in the confusion matrices presented in Figure 2. The naive Bayes classifier, for instance, frequently predicted neutral and negative sentences as positive, while the random forests classifier appears to have defaulted to neutral whenever a sentence was ambiguous. As a result, the models often predicted different sentiments for the same sentence, though in the vast majority of cases, at least three models agreed with a sentiment classification, as shown in Table 3.

The accuracy of these sentiment classifiers is low compared to existing data science research on sentiment classification, which with comparably simple methods and comparably small sample sizes has been capable for nearly two decades of obtaining accuracies in the realm

\footnotetext{
${ }^{23} \mathrm{~A}$ few parameter changes were made at this stage: only single words, and not word pairs or triplets, were used to fit the count vectorizer, and no maximum number of words was set. In addition, to ensure that the accuracy score was reliable despite the much smaller sample size, $8 \%$ of sentences, or 400 sentences, were used for testing as opposed to the more modest $5 \%$ used before.
} 

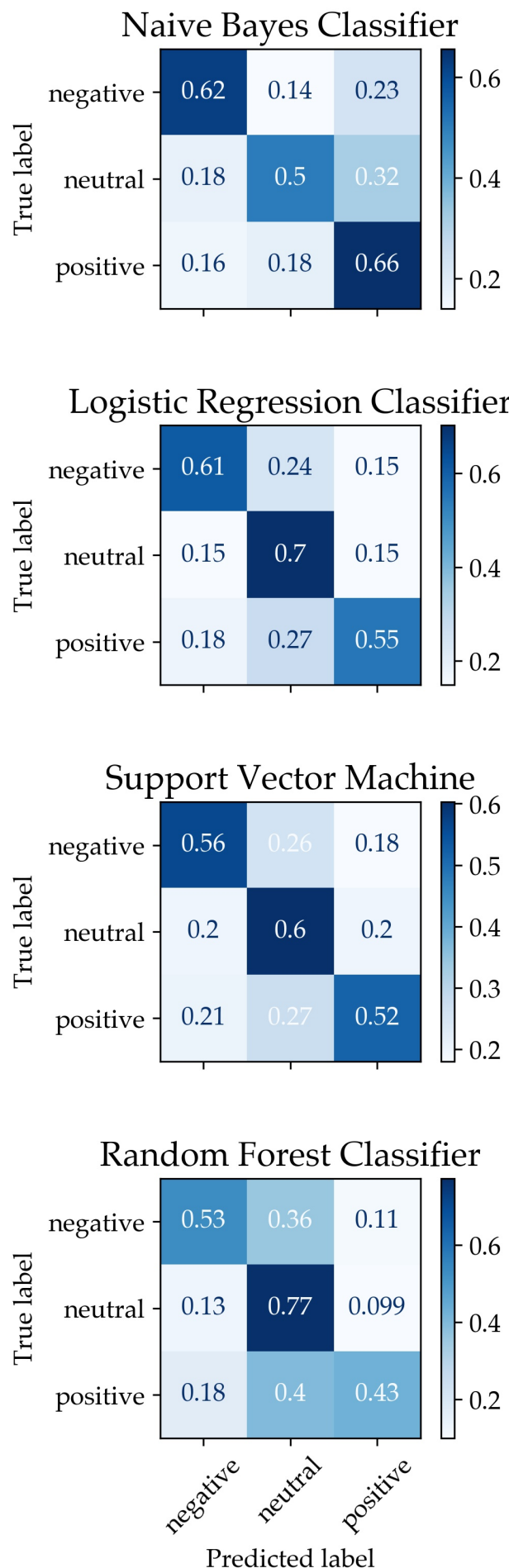

Figure 2: Confusion Matrices for Four Classifiers
Table 3: Sentiment Classifier Agreement

\begin{tabular}{lr}
\hline Model Agreement & Percent \\
\hline Unanimous & $45.9 \%$ \\
Three Agree & $36.8 \%$ \\
Two Agree & $17.3 \%$ \\
\hline
\end{tabular}

of $75-82 \%{ }^{24}$ This difference can primarily be attributed to the complexity of the texts used in this research ${ }^{25}$ Whereas previous research has tended to use data sources such as movie reviews and tweets-which are generally intended to convey strong sentiments and use comparatively simple linguistic constructions-this research instead used a greater deal of academic and journalistic writing, much of which often tends to consider multiple issues-both good and bad-within a single sentence. In addition, much writing about CRISPR tends to convey negative words even when the actual sentiment is positive: "dramatic population collapse," for instance, is a phrase that carries extremely strong negative sentiment-unless one is talked about the potential of gene drives to eliminate malaria-carrying mosquito populations ${ }^{26}$ When these factors

\footnotetext{
${ }^{24}$ See, for instance, Bo Pang, Lillian Lee, and Shivakumar Vaithyanathan, "Thumbs Up? Sentiment Classification Using Machine Learning Techniques," Proceedings of the Conference on Empirical Methods in Natural Language Processing (July 2002): 83.

${ }^{25} \mathrm{An}$ additional distinguishing feature between this research and that of Pang et al. is that the latter classified text only into positive and negative categories, whereas this research used a third neutral category.

${ }^{26}$ Because sentiment labeling is also an exercise that is highly prone to bias, it is worth mentioning a few heuristic rules that I used in assigning labels to sentences. (1) As much as possible, I attempted to follow intuitive impressions that I believed the average reader was meant to receive. When a sentence mentioned possible cures or therapies for debilitating diseases, for instance, I labeled the sentence positive, unless the majority of the sentence was spent describing the difficulties of the disease itself, in which case I labeled it negative. (2) Some exceptions to the above rule were made when the sentence in question had no strong sentiment but implied a negative sentiment. The sentence "I never felt I was discriminated against," for instance, is facially good, but implies a background set of worries about the possibility of discrimination. As a result, this sentence was labeled negative. (3) Sentences that emphasized risks and safety issues were labeled negatively.
} 
are considered, an accuracy of $62.25 \%$ is actually surprisingly high.

After training the models, each sentence was classified using each of the four models. In addition, each model was used to assign each sentence a label probability number, obtained by subtracting the probability that the sentence was negative from the probability that it was positive. This number provides a more informative value than the predicted label itself; weakly positive sentences will have label probabilities close to 0 , while strongly positive sentences will have label probabilities much closer to 1 . Using these probabilities, it became possible to more clearly examine the different distributions of sentiment in different selections.

A few more specific questions were also addressed in examining commission reports and news articles. While the general comparisons made use of all four models, these comparisons used the predicted probabilities from the logistic regression classifier. This classifier was not only the most accurate overall, but also had the lowest and most evenly distributed rates of false predictions of positive or neg-

Even when sentences spoke of both benefits and risks, if the net result was that the reader was made conspicuously aware of the dangers of gene editing, the sentence was labeled negative. (4) Sentences discussing the potential for clinical or otherwise socially positive uses of gene editing were labeled positively, while sentences merely discussing the potential to use CRISPR to study biological phenomenon were labeled as neutral—unless such possibilities were described in unambiguously positive language. (5) Sentences emphasizing public input, open discussion, and so forth, were labeled as positive, while sentences emphasizing secretive or opaque decision-making were labeled as negative. (6) Sentences that emphasized the precision and accuracy of CRISPR were labeled as positive; sentences that emphasized developments in the patent challenges or valuations of gene editing countries were labeled as negative unless emotive language was used (e.g. "bitter dispute" labeled as negative, "innovative company" labeled as positive). (7) On rare occasions, when a sentence was meant to express itself ironically, I labeled a sentiment based on its literal interpretation, not based on the interpretation the reader was meant to receive. For instance, the sentence "The seeds in my palm optimized the farm for large-scale machinery and chemical regimens; they reduced the need for labor; they elbowed out the competition (formally known as biodiversity)" is meant to leave a negative impression. Nonetheless, due to the presence of phrases such as "optimized" and "reduced the need," this sentence was labeled as positive. ative sentiments. (All else being equal, it is in most cases more misleading to falsely label a neutral sentence as positive or negative than to label a positive or negative sentence as neutral.) The predicted probabilities obtained from the logistic regression classifier were used to compare the average sentiments of articles that contained keywords-such as "Jiankui," the name of the scientist who announced in November 2018 that he had edited the genomes of embryos which were carried to term-to the average sentiments of articles without those keywords. In addition, the trend of article sentiment over time was examined, as was the average sentiment of different articles by publication. Finally, the predicted sentiment probabilities from the logistic regression classifier were used to examine the average sentiments of commission reports over time and by country.

\section{Results}

The initial naive Bayes classifier was able to quickly detect differences between the writings of ethicists, scientists, journalists, and the reports of official commissions. With relatively little parameter tuning, the classifier easily reached an accuracy of $73.1 \%$. A confusion matrix showing the predictions of the model compared to the true labels is shown in Figure 3. This matrix indicates a few things beyond the overall accuracy of the model. First, it appears that ethicists use the most distinctive language and journalists use the least distinctive language, as $77 \%$ of sentences by ethicists but only $66 \%$ of sentences by journalists were correctly identified. This makes some degree of intuitive sense, due to the fact that-as discussed in the Text Selection section-many of the writings by ethicists were semi-public and included some reasonably complex terminology which would easily mark a sentence as originating from an ethicist. A second finding is that the highest level of interference comes between journalists and scientists; over twothirds of sentences from journalists that were incorrectly labeled were attributed to scientists. This is again consistent with what might be ex- 


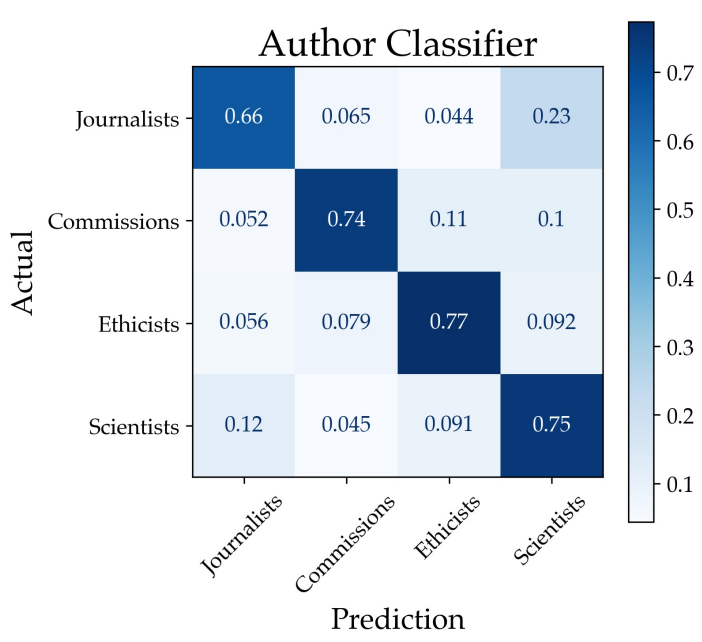

Figure 3: Confusion Matrix of Author Classifier

pected from the discussion in the Text Selection section: the texts from journalists and scientists were all written for the largest audience and are therefore the least likely to include terminological language that would serve to be highly distinguishing.

After building this text classifier, the texts were compared in finer detail. Comparing the most common words used by each type of author reveals that the four types of experts use relatively distinct language and focus on different topics, as shown in Figure 4, where words that occur among the 15 most common words for only one type of author are highlighted in blue. The 15 most common words used by scientists are the least distinctive set, which only one word-"DNA"-being frequently used by scientists but not frequently used by any other type of author. The most common word used by journalists-"say" and its non-lemmatized variants like "said"-is not used frequently by any other type of author, which makes intuitive sense, as journalists quote others frequently in their writing. Ethicists frequently use words like "moral" and "enhancement," neither of which-despite common concerns about using germline editing for enhancement purposes-break the top 15 words for any other author. Somewhat unexpectedly, commission reports appear to have the most distinctive set of most common words, with "embryo," "public," and "risk" all breaking the top 15. ${ }^{27}$ In general, the fact that "if" is very commonly used by both ethicists and scientists may indicate a willingness to emphasize uncertainty, and the fact that "human" is in the top six words for each type of author belies the fact that the overwhelming focus in discussions around gene editing has been on its applications in humans, not crops, livestock, or wild animals.

Of particular interest is the attention that each type of author pays to different aspects of the unfolding debate around gene editing therapies, such as the attention paid to the impact of gene editing on the lives of the disabled or the focus afforded to the patent dispute that has unfolded between UC Berkeley and MIT regarding the rights to commercialize CRISPR-based treatments. The different attention paid to these topics was tested by drawing up a list of 19 reasonably common and highly significant words and randomly sampling 10,000 words from each of the four corpora. The number of occurrences of each significant word from within the random sample was tabulated and the process iterated 1,000 times. Figure 5 displays the distribution of these 1,000 counts for each keyword and each type of author, with the standard deviation for each group displayed above its respective distribution plot ${ }^{28}$

The first row of words all refer to general

\footnotetext{
${ }^{27}$ Interestingly, ethicists are among the least likely to discuss embryos, an intriguing finding considering the fact that the morality of research which destroys human embryos has long been a major issue in bioethics and one of the primary areas in which bioethics have been called upon to actively help shape policy. See Thomas Banchoff, Embryo Politics: Ethics and Policy in Atlantic Democracies (Ithaca: Cornell University Press, 2011). This finding may be a result of the particular texts selected, which were focused on gene editing and not issues like research ethics or the ethics of abortion. Nonetheless, this finding at least indicates that those bioethicists who write on gene editing and human enhancement either do not care much about the debates over the moral status of the embryo or do not see a close connection between that issue and gene editing.

${ }^{28}$ Because these counts derive from random samplings of relatively rare terms, they are all Poisson distributed. The standard deviation for each sampling is therefore approximate to the square root of the mean number of times that a word occurs per sampling.
} 

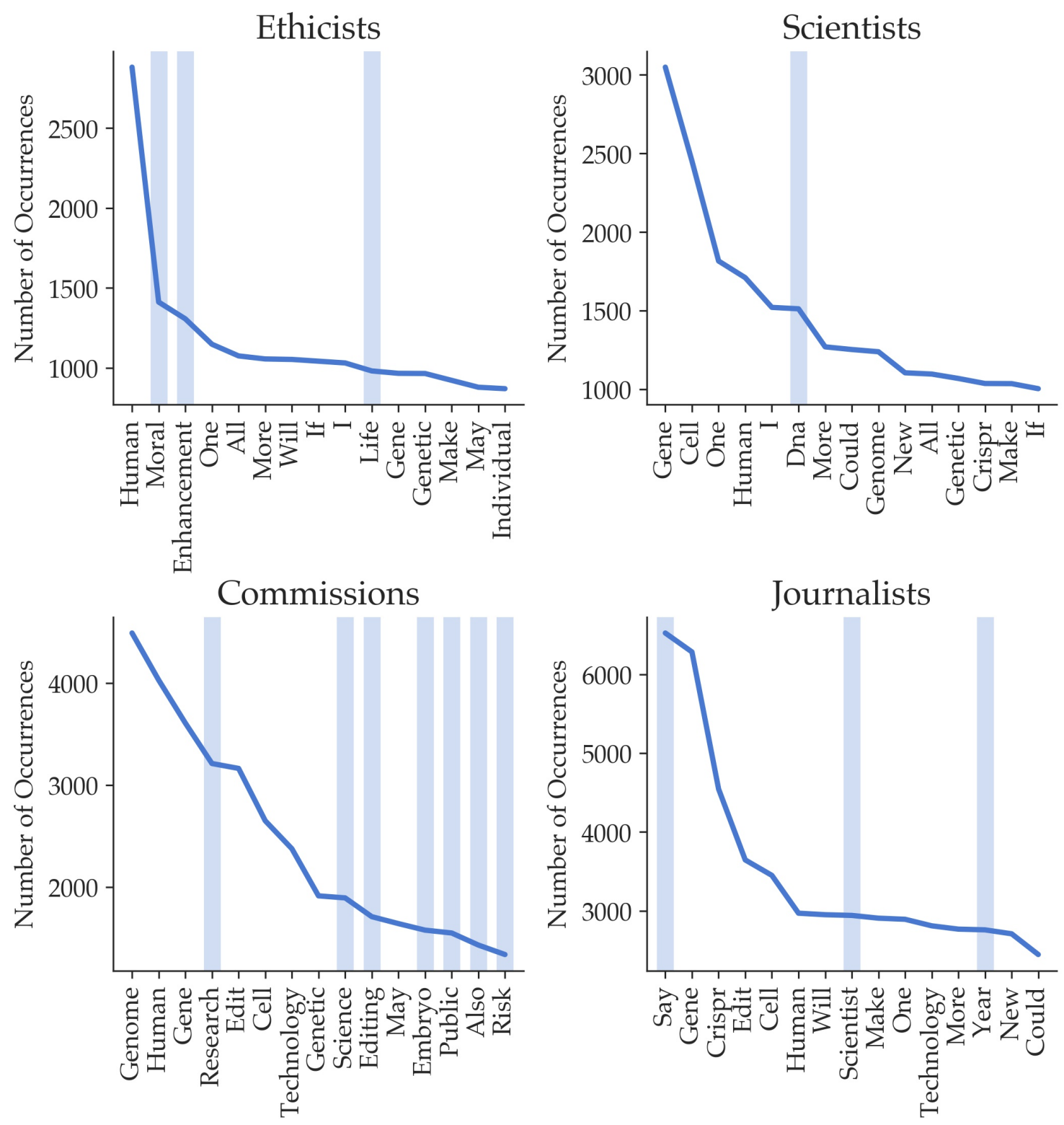

Figure 4: 15 Most Common Words by Author Type 

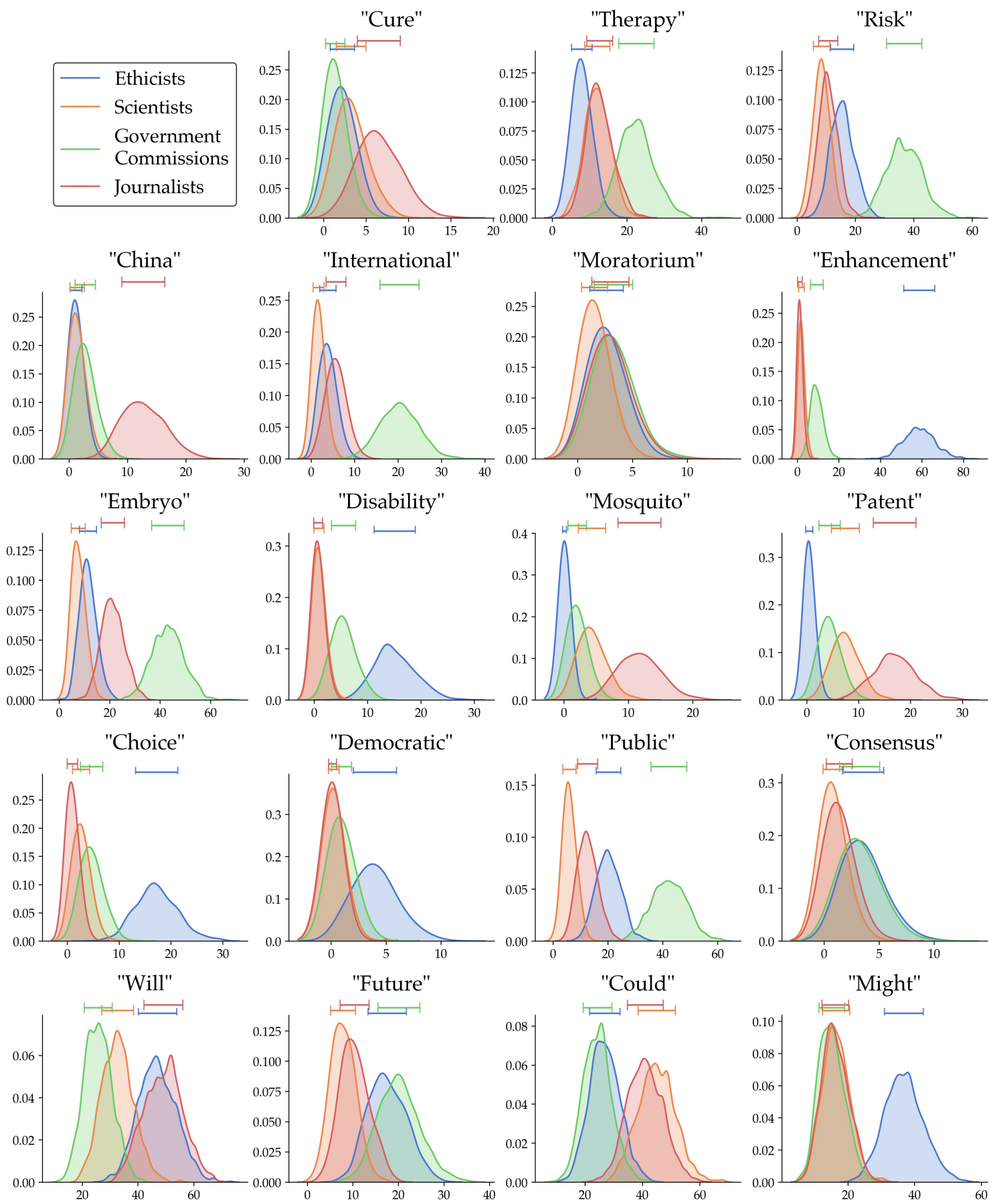

Figure 5: Frequencies of Significant Words Across 1,000 Random Samplings 
terms related to potential clinical applications of CRISPR: "cure," "therapy," and "risk." The results suggest that journalists and commissions are the most fixated on clinical applications of gene editing, with journalists preferring the somewhat-sensationalist language of cures and commissions instead preferring to speak of therapies and risks. The next two words-"international" and "China-are indicative of how different experts think of the development of gene editing in an international context. Once again, journalists and commissions are markedly more interested in international discussions than scientists or ethicists, but commissions prefer to use the collaborative term "international," whereas journalists indicate a much higher level of sensitivity to news regarding research in China. The word "moratorium" is a particularly sensitive one. As mentioned in the Introduction, a number of scientists have called for a global moratorium on human germline editing while others have resisted that label; Françoise Baylis also emphasizes the importance of the term in Altered Inheritance and criticizes Jennifer Doudna in particular and scientists in general for refusing to fully accept the word ${ }^{29}$ These findings suggest that Baylis may have a point: scientists do tend to use the word moratorium significantly less than other types of authors; nonetheless, the difference is not enormous.

The next five words all emphasize different aspects or applications of gene editing technology. Government commissions are by far the most likely to discuss germline editing and to mention embryos. Journalists instead tend to cover the ongoing patent dispute between UC Berkeley and MIT and express far more enthusiasm about the potential to use CRISPR as a means to control mosquito populations and reduce malaria. When it comes to the impact of gene editing on the lives of the disabled, however, it is ethicists who are by far the most interested. Commissions do speak of disability to a more moderate extent, but scientists and journalists display almost no interest in the topic.

\footnotetext{
${ }^{29}$ See Baylis, Altered Inheritance, 164-165.
}

The next set of four words emphasize different aspects of the decision-making process regarding how to regulate and use CRISPR. Ethicists speak the most of choice, though it is unclear what type of choices are being emphasized: perhaps choices among policy options, choices among treatments, choices among reproductive technologies, or some other type of decision presented by gene editing technologies. In general, ethicists and commissions seem to be the most concerned about how decisions regarding gene editing technologies will be made: ethicists are the most likely to contextualize these debates within the frameworks of democracy and democratic decision-making, while commissions are the most likely to talk about the public and the need for public engagement. These two groups are also the two most likely to emphasize the importance of consensus in decision-making procedures. These findings are intriguing, considering the fact that I have described the writings of journalists and scientists as public but much of the writings of ethicists and commissions as only semi-public; it is somewhat odd that the writings directed at the widest audience appear the least concerned with how the average citizen should conceive of his or her own responsibility and capacity to shape the future of gene editing technologies.

The final set of words are meant to act as proxies for an author's willingness to speculate about the future. These last four words include both directly speculative language- -will" and "future"—and weakly speculative language like "could" and "might." Here it appears there is no reliable pattern. Ethicists are among the most common users of three of these four words, commissions commonly use the word "will" but none of the others, and scientists frequently use "could" but none of the others. In general, it appears that ethicists may be the most speculative and scientists the least, though this conclusion is only a generalization from somewhat inconsistent data.

This method of random sampling and counting for keywords is deeply informative. It is nevertheless also rather poorly suited for 
Table 4: Mentions of Key Phrases by Author Type

\begin{tabular}{lrrrr}
\hline Phrase & Ethicists & Scientists & Commissions & Journalists \\
\hline "Gelsinger" & 8 & 20 & 1 & 8 \\
"AquAdvantage" & 0 & 6 & 3 & 7 \\
"Salmon" & 2 & 27 & 14 & 70 \\
"Glybera" & 5 & 10 & 0 & 0 \\
"Asilomar" & 3 & 35 & 23 & 20 \\
"Oviedo" & 3 & 0 & 69 & 0 \\
"Brave New World" & 15 & 7 & 2 & 8 \\
\hline
\end{tabular}

words which carry extreme significance but are very rarely used and are therefore unlikely to occur much even in a random sampling of 10,000 words. The name "Gelsinger," for instance, refers to Jesse Gelsinger, a teenager who died in 1999 as a result of a risky gene therapy at the University of Pennsylvania in which both the university and the lead researcher had financial stakes 30 The mere mention of the name "Gelsinger" is highly significant, as its invocation indicates that the author is raising the specter of unethical science and unsafe treatments that could put lives at risk. A number of such highly significant words are worth mentioning:

1. "Gelsinger": significant for the reasons described above.

2. "AquAdvantage" and "salmon": when invoked, either of these words reliably refers to the saga of the first genetically-engineered animal intended for human consumption, a salmon produced by AquAdvantage in 1989. Despite the fact that the salmon was found to be safe for consumption and to have no major impact on the environment, it was not approved by U.S. lawmakers until 20 years after AquAdvantage first submitted data to the FDA for approval, largely as a result of lobbying by special interests. This is nearly always interpreted as a story of unscientific overregulation, and while the mention of Jesse Gelsinger is generally meant to inspire caution, the mention of AquAdvantage is generally meant to

\footnotetext{
${ }^{30}$ See Daniel S. Greenberg, Science for Sale: The Perils, Rewards, and Delusions of Campus Capitalism (Chicago: University of Chicago Press, 2007), 104-106.
}

create suspicion of onerous regulation.

3. "Glybera": Glybera, formally known as alipogene tiparvovec, was the first gene therapy approved for commercial use, introduced in the EU in 2012. It quickly became the world's most expensive drug at a roughly one million dollar cost for a one-time dose, was administered only once to a paying customer, and was removed from the market in 2017. When invoked, mentions of Glybera reliably occur in contexts in which authors discuss the possibility that gene editing may prove effective but hopelessly out of reach for most people.

4. "Asilomar" and "Ovideo": the names of two previous and successful conventions, mentions of the Asilomar Conference on Recombinant DNA and the Oviedo Convention reliably draw attention to the way in which gene editing technologies might logistically be governed by international agreements. Usually this attention is optimistic, though these conventions may also be mentioned to highlight the difficulties with gene editing technologies that earlier technologies did not pose. The Asilomar Conference was a meeting of scientists that resulted in a voluntary moratorium on recombinant DNA research; this conference is often regarded by scientists as a successful example of scientific self-regulation, though not all observers agree that the conference reached the best conclusions. The Oviedo Convention is an international treaty among states that sets out guidelines for medical research using human biological and genetic material, and represents the current standing international framework for genetic technologies. 
An Examination of Expert Discourse on Human Genome Editing • January 2020

Table 5: Predicted Labels by Source and Classifier

\begin{tabular}{llrrr}
\hline \multicolumn{1}{c}{ Classifier } & Author Type & Negative Labels & Neutral Labels & Positive Labels \\
\hline \multirow{3}{*}{ Naive Bayes } & Ethicists & $8070(52.5 \%)$ & $2945(19.2 \%)$ & $4347(28.3 \%)$ \\
Classifier & Scientists & $5997(31.9 \%)$ & $6346(33.8 \%)$ & $6441(34.3 \%)$ \\
& Commissions & $9389(43.8 \%)$ & $5282(24.7 \%)$ & $6741(31.5 \%)$ \\
& Journalists & $14574(32.8 \%)$ & $13337(30.0 \%)$ & $16509(37.2 \%)$ \\
\hline \multirow{2}{*}{ Logistic } & Ethicists & $5636(36.7 \%)$ & $5970(38.9 \%)$ & $3756(24.4 \%)$ \\
Regression & Scientists & $4787(25.5 \%)$ & $9164(48.8 \%)$ & $4833(25.7 \%)$ \\
Classifier & Commissions & $6971(32.6 \%)$ & $9703(45.3 \%)$ & $4738(22.1 \%)$ \\
& Journalists & $11846(26.7 \%)$ & $19641(44.2 \%)$ & $12933(29.1 \%)$ \\
\hline \multirow{3}{*}{ Support Vector } & Ethicists & $5846(38.1 \%)$ & $5495(35.8 \%)$ & $4021(26.2 \%)$ \\
Machine & Scientists & $5651(30.1 \%)$ & $8133(43.3 \%)$ & $5000(26.6 \%)$ \\
& Commissions & $7847(35.0 \%)$ & $8885(41.5 \%)$ & $5040(23.5 \%)$ \\
& Journalists & $13207(29.7 \%)$ & $17911(40.3 \%)$ & $13302(29.9 \%)$ \\
\hline \multirow{2}{*}{ Random Forest } & Ethicists & $4747(30.9 \%)$ & $7647(49.8 \%)$ & $2968(19.3 \%)$ \\
Classifier & Scientists & $4106(21.9 \%)$ & $10990(58.5 \%)$ & $3688(19.6 \%)$ \\
& Commissions & $5949(27.8 \%)$ & $11483(53.6 \%)$ & $3980(18.6 \%)$ \\
& Journalists & $10031(22.6 \%)$ & $23831(53.6 \%)$ & $10558(23.8 \%)$ \\
\hline
\end{tabular}

5. "Brave New World": this phrase is the most easily recognizable on this list and generally represents a broad placeholder for the diffuse fear that new technologies-especially genetic technologies-may have deep societal consequences that ultimately serve to undermine human dignity or otherwise result in a disturbing new reality.

The total number of sentences for each type of author which contained these key words and phrases is shown in Table 4, though it should be remembered that this corpus included two to three times as many sentences from journalists as any other type of author. Nonetheless, scientists mention Glybera and Jesse Gelsinger more than any other type of author, indicating a willingness to seriously consider the possible need for greater scientific restraint and for the potential expense of new gene editing treatments. Scientists are also, however, the most likely to mention the Asilomar Conference-an example of successful scientific self-regulation in the face of a new technology. Journalists, on the other hand, are more likely to prime their readers to worry about overregulation by mentioning AquAdvantage and its salmon product.
Commissions and ethicists both generally appear cautious about drawing conclusions from these unique historical cases, though commissions often and unsurprisingly mention the Oviedo Convention, the most significant international treaty regarding genetic research. Ethicists, despite their unwillingness to discuss these concrete historical issues, are nonetheless willing to mention "Brave New World" more frequently than any other type of author, perhaps suggesting a willingness to treat the debate around gene editing in highly general terms and to treat seriously the vague and nebulous uneasiness with gene editing technologies that many people may feel at times.

After analyzing the types of words most used by each type of expert, I next turned to analyze the texts using the four sentiment classifiers discussed in the Methods section. The breakdown of the predicted labels by author type and by classifier are shown in Table 5 . Again, a few key trends stand out. First, some classifiers are more prone to extremes than others: the naive Bayes classifier predicts fewer neutral sentences for each type of author than any other classifier, and the random forest clas- 


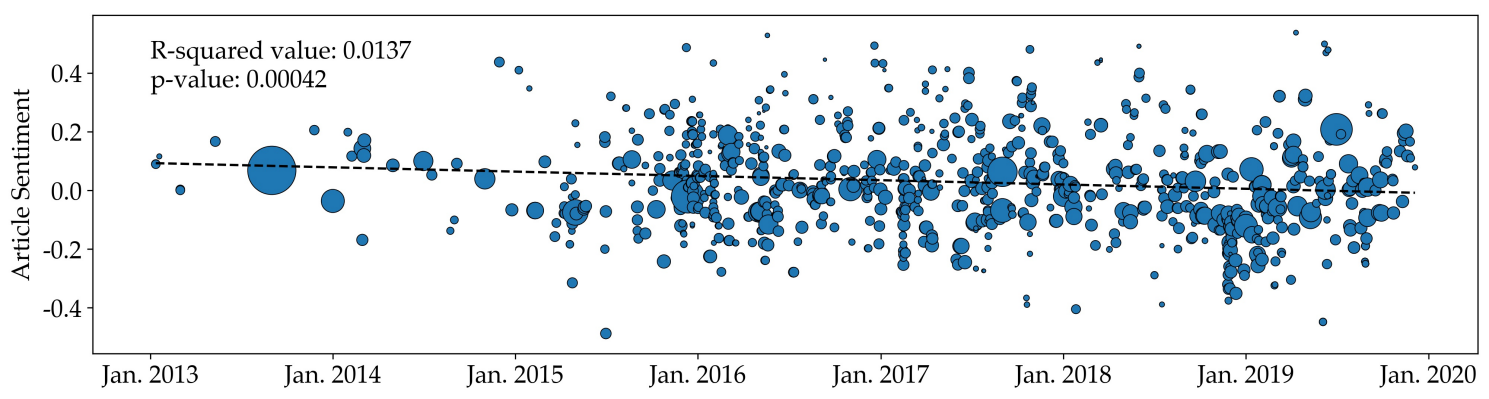

Figure 6: Average Article Sentiments by Time and Publication

sifier predicts the largest number of neutral sentences. Regardless of classifier, however, ethicists consistently have the highest percentage of negative sentences and journalists consistently have the highest number of positive sentences. However, journalists do not necessarily have substantially more positive sentences than negative sentences, whereas ethicists and commissions both reliably are labeled with far more negative sentences than positive sentences. Scientists and journalists appear to be the closest in similarity to one another, with any given prediction reliably falling within five percentage points of the corresponding prediction for the other. Although these classifiers are all prone to many difficulties-see the discussion of the difficulties with sentiment classification in the Methods section-these findings provide some reasonably compelling data to suggest that ethicists are the most negative in their discussions regarding gene editing, followed by official commissions 31

Sentiment analysis can also be used to examine changes in sentiment over time or by publication source. Figure 6 uses predicted sentiment probabilities-calculated as the probability that a sentence is positive minus the probability that it is negative- to examine changes in sentiment in news articles over time. The size of the points in Figure 6 correspond to the length of the article, while the location of the

\footnotetext{
${ }^{31}$ This is consistent with the fact that commissions tend to emphasize words like "risk" the most. Recall from the Methods section that sentences which focused strongly on the risks associated with gene editing were labeled as negative for the purposes of classifier training.
}

point itself corresponds to the average sentiment probability of all sentences within the article. A linear regression indicates a very slight but highly significant trend towards more negative articles over time, though this tendency is likely in large part due to the slate of negative articles published immediately following the announcement of the first "CRISPR babies" in November 2018. Interestingly, the other clear cluster of articles-published in February 2017 in response to the release of the NASEM reports-are also generally negative in sentiment, though by a smaller margin. The timeline also indicates that there has been little progress towards anything resembling a consensus among journalists; if anything, the articles have become even more variable in their sentiment over time.

These predicted sentiment probabilities can also be used to examine the sentiment of articles that do and do not include specific key words. Three such comparisons are presented in Figure 7. The first represents a comparison between the average sentiment of articles that mention He Jiankui, the average sentiment of articles that mention China but not He Jiankui, and the average sentiment of articles that mention neither China nor He Jiankui. This comparison reveals that articles mentioning He Jiankui are significantly more negative than either of the other two sets of articles ( $\mathrm{p}<0.005$ for both comparisons). But it also reveals that articles mentioning China but not He Jiankui are significantly more negative than articles mentioning neither $(\mathrm{p}<0.005)$. To further explore the way that China is portrayed by 


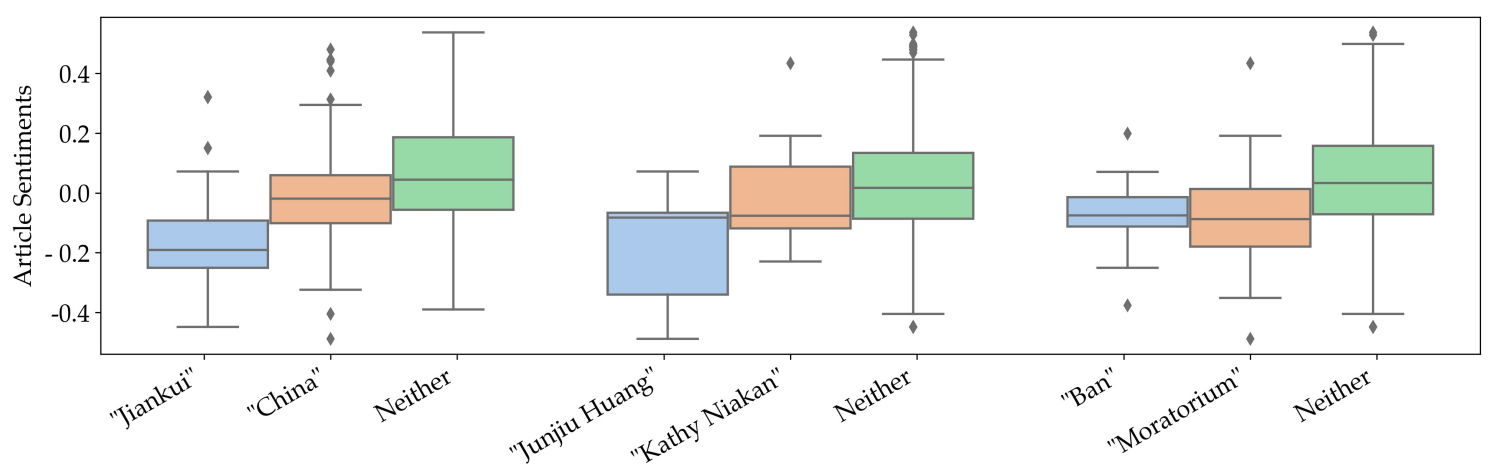

Figure 7: Article Sentiments Based on the Presence or Absence of Key Words

journalists, similar comparisons can be made between articles mentioning Huang Junjiu but not Kathy Niakan, articles mentioning Kathy Niakan but not Huang Junjiu, and articles mentioning neither. Huang Junjiu was the first researcher to announce, in April 2015, that he had edited the genes of nonviable human embryos in a research experiment, while Kathy Niakan is an American-born researcher working in Britain who became the first Western scientist to have similar research approved. Although the researchers had somewhat different aims-Dr. Huang's research was meant to assess the risks associated with a potential clinical application of CRISPR while Dr. Niakan's research was meant to examine embryonic development-the type of research performed by each was very similar ${ }^{32}$ Despite the similarity

\footnotetext{
${ }^{32}$ It is also worth noting that Dr. Huang's research was covered in the press only after it was published in a low-tier journal after being rejected by Nature and Science for ethical reasons, while most coverage of Dr. Niakan's research occurred just after her proposed research was approved by a regulatory body in the United Kingdom. While some media reports portrayed Dr. Huang's research as overstepping boundaries commonly accepted in the West-see Didi Kirsten Tatlow, "A Scientific Ethical Divide Between China and West," New York Times, June 29, 2015-the international consensus at the time of his experiments roughly held that it was far too premature to use CRISPR for any clinical treatments, especially germline treatments, but that the issue might be revisited later if the accuracy of CRISPRbased editing could be further studied and significantly improved. Dr. Huang's research on nonviable human embryos, which was primarily an attempt to test the accuracy of CRISPR as a clinical tool, therefore seems to fall within the range of research not prohibited by international
}

of the research conducted by the two scientists, articles mentioning Huang Junjiu but not Kathy Niakan were once again significantly more negative than articles that mentioned neither researcher, and somewhat more negative than articles mentioning Kathy Niakan but not Huang Junjiu, though not quite enough to meet the threshold for statistical signfiicant $(\mathrm{p}=0.0568)$. Articles mentioning Kathy Niakan but not Huang Junjiu were more negative than articles mentioning neither researcher, though not by any reasonable degree of significance $(p=0.790)$. Taken together, the data regarding articles mentioning He Jiankui and Huang Junjiu suggest that journalists tend to write more negatively about research conducted in China independently of whether that research is different from research conducted in the West.

The final comparison in Figure 7 examines the average sentiment of articles containing the word "ban" (but not "moratorium"), the average sentiment of articles containing the word "moratorium" (but not "ban"), and the average sentiment of articles containing neither word. The results may provide support to those scientists who avoid the word "moratorium" because they believe it will lead people to believe that the technology has been banned outright: journalists write more negatively in articles containing either word but do not appear to

consensus at the time, and perhaps even endorsed by the consensus insofar as such research would be necessary to more thoroughly quantify the safety risks of CRISPR-based editing. 
Table 6: Commission Sentiments by Region

\begin{tabular}{lr}
\hline Region & Average Sentiment \\
\hline United States & -0.135 \\
United Kingdom & -0.051 \\
Australia & -0.084 \\
Netherlands & -0.129 \\
Europe & -0.056 \\
OECD & -0.013 \\
Germany & -0.178 \\
International & -0.171 \\
France & -0.079 \\
New Zealand & 0.077 \\
Denmark & -0.117 \\
\hline
\end{tabular}

moderate the sentiment of their writing based on the difference between the word "ban" and the word "moratorium" ( $\mathrm{p}=0.767)$.

Lastly, this method of examining sentiment probabilities can be used to compare the sentiments of different commission reports. Specifically, two key areas of interest are in the way that the sentiment of these reports changes over time and based on country of origin. Figure 8 shows the change in report sentiment over time with the length of different reports indicated by the size of the marked point. Plotting a linear regression shows a more pronounced negative trend than is observed among journalists; however, the $p$-value for this regression is not statistically significant. (This is primarily due to the fact that both regressions use only the average sentiment of all sentences in each report regardless of size; the dataset for journalists therefore has 904 unique data points, while the dataset for commissions has only 27 unique data points. When the regression for commission reports is weighted by the total number of sentences in each report, the trend line becomes slightly more negative, the R-value rises to 0.1363 , and the $p$-value becomes negligibly small.)

To compare the sentiments of reports from different countries and regions, each report used in this research was grouped into the smallest applicable geographical region. If the composition of the commission included participants from multiple continents, it was classified as "international. 33 Table 5 lists the different countries and regions that produced reports and the average predicted sentiment of all reports from that region, weighted by length. The reports are listed in descending order of cumulative length ${ }^{34}$ These comparisons suggests that Germany is the most negative towards gene editing technologies, which is a somewhat expected result; Germany has a history of being particularly cautious around biotechnology and embryonic research, a legacy which is in many ways a result of historical sensitivity to anything that appears to resemble eugenics ${ }^{35}$ Intriguingly, reports issued by broad international commissions are the second most negative, and reports from the United States-or rather report, since the only American report included in this research was the 2017 NASEM report-is the third most negative. This last finding is particularly surprising, since the NASEM report was widely regarded at the time it was published as expressing an unprecedented level of openness to potential future uses of human germline editing; indeed, it was permissive enough that He Jiankui used its conclusions to defend the claim that his research was consistent with international standards (though this claim was not well supported by the actual conclusions of the NASEM report) 36

\footnotetext{
${ }^{33}$ The exception is reports from OECD working groups, which were instead labeled as "OECD."

${ }^{34}$ One report from the Spanish Bioethics Committee has been excluded because it is the only report from Spain but its size - at only 13 sentences-is far too small to draw any reasonable conclusions. All other reports regions had reports totaling to at least 225 sentences in length, and all regions except Denmark, New Zealand, and France had reports summing to at least 1,000 sentences in length. For a full list of the reports associated with each region and their lengths, see Table A1 in the Appendix.

${ }^{35}$ See Banchoff, Embryo Politics for a more sustained discussion of this historical legacy.

${ }^{36}$ See Antonio Regalado, "Rogue Chinese CRISPR scientist cited US report as his green light", MIT Technology Review, November 26, 2018, https:/ / www.technologyreview.com/s/612472/roguechinese-crispr-scientist-cited-us-report-as-his-greenlight/.
} 


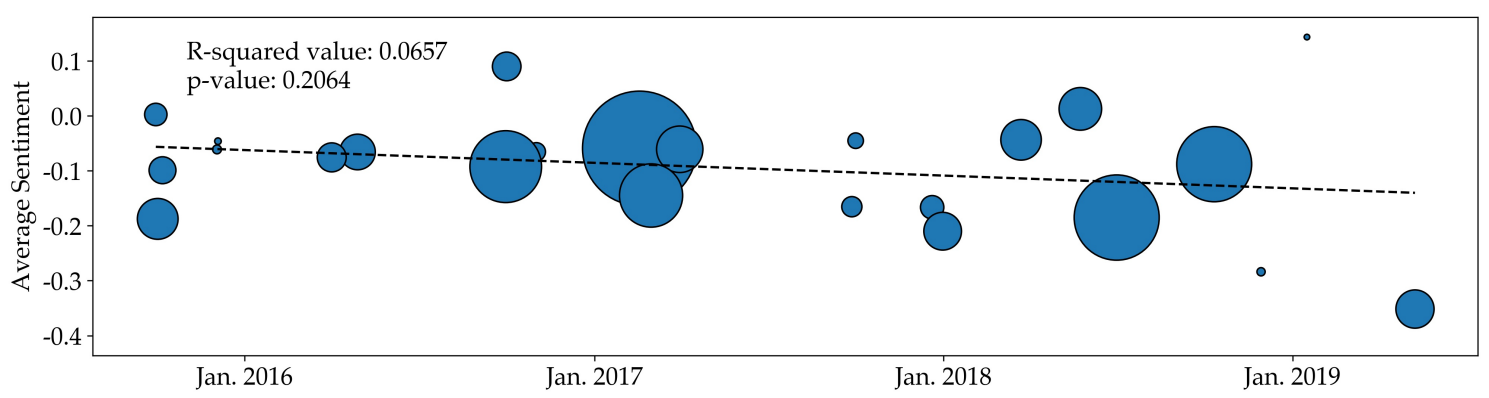

Figure 8: Average Sentiment of Commission Reports Over Time

\section{Discussion}

In this paper, I have attempted to explore a large dataset of roughly 100,000 individual sentences by ethicists, scientists, official commissions, and journalists written on the topic of human genome editing. Although this research was framed with a few guiding questions, the goal was to attempt to understand as holistically as possible the differences between the communication styles used by each type of expert. Throughout, I have used a wide array of methods to explore different questions and have preferred to present what appear to be the most sensible interpretations of the results alongside the results themselves. I do not here wish to attempt any sort of evaluative comparison of the validity of different communication styles adopted by different experts, nor do I believe that this research provides a high enough degree of confidence to make sweeping claims about the perspectives of any particular group of authors. It should be remembered-as discussed in the Text Selection section-that the decision to write about this topic is itself a strongly selective factor, such that even if my results validly describe the perspectives of, say, all scientists who have written books on gene editing, this does not mean that the conclusions are generalizable to scientists as a class. In addition, those results which are obtained by directly comparing objective features such as word frequencies inspire greater confidence than results obtained by using the sentiment classifier trained for this research, as sentiment classification is a highly subjective enterprise.
Even were sentiment classification an objective activity, the reasonably low degree of accuracy obtained from training sentiment classifiers on pre-labeled data should limit the level of confidence used in interpreting the sentiment-based results of this research.

Nonetheless, this research was in many ways remarkably robust. All datasets were reasonably large and it was possible to obtain commission reports and news articles in a way that could be clearly articulated with minimal bias. Moreover, though the sentiment classifiers did not achieve high degrees of accuracy, the mistakes made by the logistic regression classifier-which was used for all of the detailed analysis of news articles and commission reports-were highly evenly distributed. Although these conclusions cannot be taken as truth, we may at least have a high degree of confidence that they more or less accurately describe the trends in the underlying data. Using the combined research methods outlined above, a few trends do appear to stand out.

First, sentiment towards gene editing appears to be most negative among ethicists, but also fairly negative on the whole among government commissions. It should be remembered that in labeling, sentences which primarily focused on risk were labeled as "negative," even if they also mentioned potential benefits. With this in mind, it makes some degree of sense that commissions tend to be rather negative, insofar as commissioners, having been entrusted to help shape public policy, may be likely to acutely feel their responsibility to minimize risks for anyone who may eventually use 
clinical treatments based on gene editing technologies. In addition, there appears to be a slightly negative trend in sentiment towards CRISPR over time among both journalists and commissions, though it is unclear to what extent this trend is merely the result of the highly negative reaction to the Jiankui experiments in November 2018.

Different aspects of the gene editing discourse also appear to interest different types of experts. Ethicists and commissions appear the most interested in questions regarding regulatory decision-making, frequently using words such as "public," "democratic," and "consensus." Yet while ethicists discuss the issue of democratic procedures and appear willing to closely examine the ethics of using gene editing technologies-an interest expressed by the frequency of words like "choice," "enhancement," and "moral"-they appear less willing as a class to explore the way that new technologies will interact with broad social structures. Ethicists as a class rarely mention Glybera and appear to have taken virtually no interest in the patent dispute between UC Berkely and MIT over the rights to commercialize CRISPR. This suggests that ethicists do not, as standard practice, contextualize the question of whether and how to pursue gene editing technology within the related question of how to ensure that medical technologies are accessible to all and used for the betterment of society rather than the profit of patent-holders. These findings suggest that bioethicists have not necessarily followed the prescriptions of John Dewey, who, in the words of Elizabeth Anderson, argued that "the primary problems for ethics in the modern world [concern] the ways society ought to be organized, rather than personal decisions of the individual. 37

Scientists appear to use the least distinctive language. Of the most common 15 words used by scientists, only the technical term "DNA" does not appear in the most common 15 words of any other author. Books by scientists do

\footnotetext{
${ }^{37}$ Elizabeth Anderson, "Dewey's Moral Philosophy," Stanford Encyclopedia of Philosophy, July 17, 2018, https://plato.stanford.edu/entries/dewey-moral/.
}

not focus as much as journalists or commissions on the potential clinical applications of CRISPR technology, as words like "cure," "therapy," and "risk" are all used only rarely. Scientists are on average, however, the most likely to use concrete historical cases-such as the Jesse Gelsinger case, the Glybera failure, and the Asilomar Conference-to frame their discussions. Scientists are also in general the least likely to use strongly speculative language; when discussing the future, they tend to default to the weaker term "could." This is somewhat surprising given the types of subtitles attached to the books by scientists used in this analysis, which, in no particular order, run as follows: How Gene Editing Will Rewrite Our Futures, How Synthetic Biology Will Reinvent Nature and Ourselves, Editing the Human Genome with Crispr-Cas9, Gene Editing and the Unthinkable Power to Control Evolution, and Redesigning the Future of Humanity-One Gene at a Time. If anything, this disjuncture between subtitles and actual texts suggests that scientists face the strongest pressures from editors to sensationalize their writing in order to attract wider audiences.

Journalists as a whole express the greatest interest both in the patent dispute shaping the future of CRISPR and in the potential to use gene editing and gene drives to eliminate malariacarrying mosquito populations. Another major finding of this research is that, far more than any other type of author, journalists display a persistent and strongly negative fixation on China. Whereas commissions emphasize the international aspect of gene editing decisionmaking, journalists tend to focus exclusively on the role played by China. It is perhaps understandable that articles mentioning China would carry a negative sentiment overall due to the fact that many such articles have been written about He Jiankui, whose research was condemned by Chinese scientists as rapidly as Western scientists ${ }^{38}$ Nonetheless, even ar-

\footnotetext{
${ }^{38}$ Within a day of his announcement, 122 leading Chinese scientists had signed a letter condemning Jiankui's actions. See Rob Stein, "Facing Backlash, Chinese Scientist Defends Gene-Editing Research on Babies," NPR,
} 
ticles that mention China but not Jiankui are significantly more negative in their sentiment than articles that mention neither. Furthermore, the press appears to describe Chinese research more negatively than Western research even when research projects are highly similar, as the comparison of Huang Junjiu and Kathy Niakan suggests. This is a point that was made shortly after regulatory approval of Niakan's research by the Chinese bioethicist Renzong Qiu, who in an op-ed submitted to but not published by the New York Times argued that Western media's portrayal of Dr. Huang's research as deeply unethical was inconsistent with its portrayal of Dr. Niakan's research ${ }^{39}$ Although the sentiment analysis conducted here does indicate that articles regarding Dr. Niakan's research were somewhat more negative than the average article about CRISPR, Dr. Qiu's point is more or less supported by the data: journalists appear more hostile towards or afraid of Chinese research, even when that research is highly similar to research conducted in the West 40

November 28, 2018, https:/ / www.npr.org/sections/healthshots/2018/11/28/671375070/facing-backlash-chinesescientist-defends-gene-editing-research-on-babies. Meanwhile, the Second International Summit on Human Genome Editing - at which Jiankui made his announcement-condemned the research but did not mention Jiankui by name, limited the discussion of the issue to a single terse paragraph in its closing statement, and appears to have taken a more permissive stance towards future clinical applications than previous conferences despite the new revelations. This last fact is suggested by the citation of the NASEM report and the 2018 Nuffield Council report as existing frameworks to build upon, which were both regarded as taking significant steps towards more permissive research agendas at the times of their respective publications.

${ }^{39}$ See Renzong Qiu, "Debating Ethical Issues in Genome Editing Technology," Asian Bioethics Review 8, no. 4 (December 2016): 318.

${ }^{40}$ Admittedly, it is possible that the negative sentiment towards China could have resulted if the random selection of 5,000 training sentences contained primarily sentences that portrayed China or Chinese researchers negatively. If that were the case, the labeled sentences would have biased each classifier model to interpret the word "China" itself as a negative word. However, this explanation, if true, would be the result of a random sampling which included several hundred sentences mentioning China. If many or most of those sentences were negative in sentiment, that is likely the result of an predisposition against Chinese research in
It is difficult to stress sufficiently the caveats with which these findings must be interpreted. As I have continually emphasized, these findings are the result of a limited sample of texts which are likely not perfectly representative of each expert class's perspective as a whole. Nonetheless, this analysis has returned many intriguing results which can inspire some reasonably high degree of confidence. Hopefully, this attempt to apply quantitative methods to examine the unfolding discourse around human gene editing will allow experts to better understand the language used by other types of experts. Ideally, it may also provide experts an opportunity to reflect on the potential blind spots and shortcomings of their own thinking and writing regarding this critical issue.

the underlying data, and the explanation therefore fails to explain away the observed negative pattern. 
Table A1: List of Commission Reports

\begin{tabular}{|c|c|c|c|c|}
\hline Publication Date & Title & Commission & Region & Sentence Count \\
\hline September 2015 & $\begin{array}{l}\text { The Opportunities and Lim- } \\
\text { its of Genome Editing }\end{array}$ & $\begin{array}{l}\text { Germany National Academy } \\
\text { of Sciences }\end{array}$ & Germany & 245 \\
\hline October 2015 & $\begin{array}{l}\text { Report of the IBC on Updat- } \\
\text { ing Its Reflection on the Hu- } \\
\text { man Genome and Human } \\
\text { Rights }\end{array}$ & $\begin{array}{l}\text { UNESCO International } \\
\text { Bioethics Committee }\end{array}$ & International & 831 \\
\hline October 2015 & $\begin{array}{l}\text { Human Genome Surgery- } \\
\text { Towards Responsible Evalua- } \\
\text { tion of a New Technology }\end{array}$ & $\begin{array}{l}\text { Berlin-Brandenburg } \\
\text { Academy of Sciences } \\
\text { and Humanities }\end{array}$ & Germany & 335 \\
\hline December 2015 & $\begin{array}{l}\text { Statement of the First Sum- } \\
\text { mit on Human Genome Edit- } \\
\text { ing }\end{array}$ & $\begin{array}{l}\text { International Summit on } \mathrm{Hu}- \\
\text { man Genome Editing }\end{array}$ & International & 35 \\
\hline December 2015 & $\begin{array}{l}\text { Statement on Genome Edit- } \\
\text { ing Techniques }\end{array}$ & $\begin{array}{l}\text { Council of Europe Commit- } \\
\text { tee on Bioethics }\end{array}$ & Europe & 24 \\
\hline April 2016 & $\begin{array}{l}\text { Genetic Editing of Human } \\
\text { Germline Cells and Embryos }\end{array}$ & $\begin{array}{l}\text { French National Academy of } \\
\text { Medicine }\end{array}$ & France & 374 \\
\hline April 2016 & $\begin{array}{l}\text { Human Genome Editing in } \\
\text { EU }\end{array}$ & $\begin{array}{l}\text { Federation of European } \\
\text { Academies of Medicine }\end{array}$ & Europe & 525 \\
\hline September 2016 & $\begin{array}{l}\text { Genome Editing: An Ethical } \\
\text { Review }\end{array}$ & Nuffield Council & U.K. & 3,049 \\
\hline October 2016 & $\begin{array}{l}\text { Gene Editing Evidence Up- } \\
\text { date }\end{array}$ & $\begin{array}{l}\text { Royal Society of New } \\
\text { Zealand }\end{array}$ & New Zealand & 589 \\
\hline November 2016 & $\begin{array}{l}\text { Position Paper of the Royal } \\
\text { Netherlands Academy of } \\
\text { Arts and Sciences }\end{array}$ & $\begin{array}{l}\text { Royal Netherlands Academy } \\
\text { of Arts and Sciences }\end{array}$ & Netherlands & 139 \\
\hline February 2017 & $\begin{array}{l}\text { Human Genome Editing: } \\
\text { Science, Ethics, and Gover- } \\
\text { nance }\end{array}$ & $\begin{array}{l}\text { National Academies of } \\
\text { Science, Engineering, and } \\
\text { Medicine }\end{array}$ & U.S.A. & 6,389 \\
\hline March 2017 & $\begin{array}{l}\text { Ethical and Legal Assess- } \\
\text { ment of Genome Editing in } \\
\text { Research on Human Cells }\end{array}$ & $\begin{array}{l}\text { German National Academy } \\
\text { of Sciences }\end{array}$ & Germany & 178 \\
\hline March 2017 & $\begin{array}{l}\text { Editing Human DNA. Moral } \\
\text { and Social Implications of } \\
\text { Germline Genetic Modifica- } \\
\text { tion }\end{array}$ & $\begin{array}{l}\text { Netherlands Commission on } \\
\text { Genetic Modification }\end{array}$ & Netherlands & 1,783 \\
\hline March 2017 & $\begin{array}{l}\text { Genome Editing: Scientific } \\
\text { Opportunities, Public Inter- } \\
\text { ests, and Policy Options in } \\
\text { the EU }\end{array}$ & $\begin{array}{l}\text { European Academies Sci- } \\
\text { ence Advisory Council }\end{array}$ & Europe & 955 \\
\hline September 2017 & $\begin{array}{l}\text { Germline Intervention in the } \\
\text { Human Embryo }\end{array}$ & German Ethics Council & Germany & 174 \\
\hline
\end{tabular}




\begin{tabular}{|c|c|c|c|c|}
\hline Publication Date & Title & Commission & Region & Sentence Count \\
\hline October 2017 & $\begin{array}{l}\text { The Application of Genome } \\
\text { Editing in Humans }\end{array}$ & $\begin{array}{l}\text { Federation of European } \\
\text { Academies of Medicine }\end{array}$ & Europe & 100 \\
\hline December 2017 & $\begin{array}{l}\text { Statement from the Danish } \\
\text { Council on Ethics on Genetic } \\
\text { Modification of Future Hu- } \\
\text { mans }\end{array}$ & Danish Council on Ethics & Denmark & 230 \\
\hline December 2017 & $\begin{array}{l}\text { Assessing the Security Impli- } \\
\text { cations of Genome Editing } \\
\text { Technologies }\end{array}$ & InterAcademy Partnership & International & 589 \\
\hline March 2018 & $\begin{array}{l}\text { Gene Editing in an Inter- } \\
\text { national Context: Scientific, } \\
\text { Economic, and Social Issues } \\
\text { Across Sectors }\end{array}$ & $\begin{array}{l}\text { Organisation for Economic } \\
\text { Co-operation and Develop- } \\
\text { ment }\end{array}$ & OECD & 718 \\
\hline May 2018 & $\begin{array}{l}\text { Gene Editing for Advanced } \\
\text { Therapies: Governance, Pol- } \\
\text { icy, and Society }\end{array}$ & $\begin{array}{l}\text { Organisation for Economic } \\
\text { Co-operation and Develop- } \\
\text { ment }\end{array}$ & OECD & 884 \\
\hline July 2018 & $\begin{array}{l}\text { Genome Editing and Human } \\
\text { Reproduction: Social and } \\
\text { Ethical Issues }\end{array}$ & Nuffield Council & U.K. & 2,164 \\
\hline October 2018 & $\begin{array}{l}\text { Third Review of the National } \\
\text { Gene Technology Scheme }\end{array}$ & $\begin{array}{l}\text { Australian Department of } \\
\text { Health }\end{array}$ & Australia & 2,480 \\
\hline November 2018 & $\begin{array}{l}\text { Human Genome Editing: } \\
\text { Where to Draw the Line? }\end{array}$ & Royal Society of London & U.K. & 80 \\
\hline November 2018 & $\begin{array}{l}\text { Statement of the Second Sum- } \\
\text { mit on Human Genome Edit- } \\
\text { ing }\end{array}$ & $\begin{array}{l}\text { International Summit on } \mathrm{Hu}- \\
\text { man Genome Editing }\end{array}$ & International & 28 \\
\hline January 2019 & $\begin{array}{l}\text { Statement Issued by the } \\
\text { Spanish Bioethics Committee } \\
\text { on Genome Editing in Hu- } \\
\text { mans }\end{array}$ & Spanish Bioethics Committee & Spain & 18 \\
\hline May 2019 & $\begin{array}{l}\text { Intervening in the Human } \\
\text { Germline }\end{array}$ & German Ethics Council & Germany & 611 \\
\hline
\end{tabular}

